\title{
Sistem Keamanan Ruangan Dengan Perekaman Visual Berbasis Radio Frekuensi Identification Dan Pre Hypertext Processor (PHP) di Loka Monitor Spektrum Frekuensi Radio
}

\author{
Yurindra \\ Program Studi Teknik Informatika \\ STMIK Atma Luhur \\ Jl. Jend. Sudirman, Selindung, Pangkalpinang \\ yurindra@atmaluhur.ac.id
}

\author{
Agusta Dirga Saputra \\ Program Studi Teknik Informatika \\ STMIK Atma Luhur \\ Jl. Jend. Sudirman, Selindung, Pangkalpinang \\ agustadirga@gmail.com
}

\begin{abstract}
The purpose of the thesis was to produce concrete results in providing security to the agencies that require special security. The method used in the manufacture of home lighting control devices based microcontroller using android smartphone is a prototype. This research method consists of several stages, library research, analytical methods, design methods, and implementation. The results achieved are ketenanagan perceived by the security agencies in masaah increased after he made these security systems. Where this tool uses a layered security system using Radio Frequency Identification (RFID) integrated with any database access. The results of testing this tool ebrhasil well where the user can sign in using RFID card and the user is not registered will be blocked and taken kgambar as evidence.
\end{abstract}

Keywords- Security, Radio Frequency Identification, Prehypertext Processor

\section{Pendahuluan}

Perkembangan teknologi berkembang sangat pesat di kehidupan manusia. Dari informasi yang bisa diakses dimanapun dan kapanpun hingga masalah keamanan. Kemajuan teknologi turut membantu dalam pengembangan sistem keamanan yang handal. Salah satu penerapan sistem keamanan adalah untuk pengaman ruangan.

Peningkatan tingkat kriminalitas dan keahlian para pencuri yang semakin tinggi, membuat penulis memperoleh ide atau gagasan inovasi alat pengaman pintu rumah menggunakan Radio Frequency Identification (RFID) dan ATMega16 yang tentunya dengan sistem pengamanan yang tinggi. Rancangan keamanan ini tidak mengandalkan mekanik sebagai interfacenya melainkan menggunakan perangkat elektronik yang cukup sulit untuk dibobol karena selain diperlukan pengetahuan mengenai elektronik, para pelaku kriminalitas juga harus memilki pengetahuan dibidang pemrograman dan teknologi informasi. Berbeda dengan kunci mekanik, kunci elektronik pada rancangan keamanan ini menggunakan Radio Frequency Identification (RFID) sebagai pembukanya. Sistem Radio Frequency Identification (RFID) ini terdiri atas tiga komponen utama, yaitu tag atau transponder, reader, dan database. Tag RFID berfungsi sebagai alat pelabelan suatu objek yang di dalamnya terdapat sebuah data tentang objek tersebut. Kemudian reader RFID digunakan sebagai alat scanningatau pembaca informasi yang ada pada tag RFID tersebut. Sedangkan database digunakan sebagai pelacak dan penyimpan informasi tentang objek-objek yang dimiliki oleh tag RFID.

Sistem Keamanan Ruangan dengan Perekaman Visual Berbasis Radio Frequency Identification dan Sistem Pre Hypertext Processor (PHP) dirasa sangat tepat menghadapi kondisi yang saat ini dihadapi oleh perusahaan atau instansi yang mempunyai masalah besar terhadap keamanan. Sistem ini menggunakan keamanan yang berlapis mulai dari penggunaan RFID ( Radio Frequency Identification) yaitu salah satu produk dari pengembangan teknologi nirkabel yang saat ini terus di aplikasikan pada kehidupan sehari-hari. RFID sendiri terbuat dari bahan yang anti gores dan tahan air, sehingga terkesan mobile. Kemudian untuk memberikan pengamanan berlapis, maka digunakan pula Perekaman Visual untuk menagkap gambar pencuri.

\section{Metode Penelitian}

\section{A. Studi Pustaka}

Pada tahap ini dilakukan untuk mengambil beberapa data yang berasal dari berbagai sumber seperti buku, skripsi, jurnal ilmiah dan internet dimana isi dari sumber-sumber tersebut dijadikan suatu referensi dan acuan dalam penulisan ini.

\section{B. Analisis Sistem}

Analisis sistem dilakukan untuk memberikan arahan dan menentukan tahap proses pengerjaan selanjutnya dalam hal penentuan kebijakan. Analisis sistem dilakukan dengan tahap sebagai berikut: 


\section{1) Analisis Masalah}

Pada tahap ini dilakukan untuk mengetahuai masalah yang sedang terjadi pada sistem lama atau sistem yang sedang berjalan.

\section{2) Analisis sistem berjalan}

Pada tahap ini dilakukan untuk mengetahui sistem atau proses yang sedang berjalan sekarang, digambarkan dalam activity diagram.

\section{3) Analisis kebutuhan}

Pada tahap ini dilakukan untuk mengetahuai kebutuhan sistem, kebutuhan user, kebutuhan admin, kebutuhan proses, kebutuhan output perangkat keras dan perangkat lunak yang digunakan..berjalan.

\section{Perancangan Sistem}

Perancangan Sistem adalah merancang sistem secara rinci berdasarkan hasil analisis sistem yang ada, sehingga menghasilkan model baru yang diusulkan dan tergambarkan oleh diagram blok.

\section{Implementasi}

Pada tahap ini adalah proses memaparkan hasil-hasil dari instalasi perangkat keras, langkah-langkah instalasi perangkat lunak, tampilan layar dan pengujian. Pada tahap pengujian dilakukan uji coba terhadap aplikasi dengan metode Black Box. Kemudian hasil dari uji coba tersebut dievaluasi. Apabila terdapat kesalahan atau kekurangan pada aplikasi tersebut, maka dapat dilakukan perbaikan yang diperlukan.

\section{PEMBAhasan}

\section{A. Analisa Sistem}

Kegiatan analisis sistem memegang kunci penting dalam memberikan arahan permasalahan dan menentukan tahap proses pengerjaan selanjutnya dalam hal penentuan kebijakan.

1) Analisa masalah

Berdasarkan hasil penelitian dan pengamatan penulis, masalah yang ada pada Loka Monitor Spektrum Frekuensi Radio adalah :

a) Minimnya sistem keamanan ruangan pada kantor Loka Monitor Spektrum Frekuensi Radio Pangkalpinang, saat ini masih mengunakan system kunci biasa yang sangat rentan terhadap pencurian atau penyalahgunaan data yang ada di ruangan tersebut.

b) Akses keluar masuk tidak terkontrol karena tidak mempunyai laporan keluar dan masuk ruangan terhadap penggunaan ruangan tersebut.

\section{2) Analisa proses berjalan}

Dalam system control akses pintu server yang sedang berjalan yaitu pintu akses ke ruangan server bisa dimasuki siapa saja tanpa ada batasannya dalam hal ini system pengaksesannya masih tergalong belum standard karena siapa saja bisa saja masuk dan akses ke ruangan tersebut. Diperlukan sebuah sarana baru untuk mengatasi masalah tersebut, sebuah system pintu otomatis dengan barcode scanner bisa membatasi pengaksesan akses ke ruangan tersebut. Berikut adalah Activity diagram yang mengacu pada system yang sedang berjalan sebagai berikut :

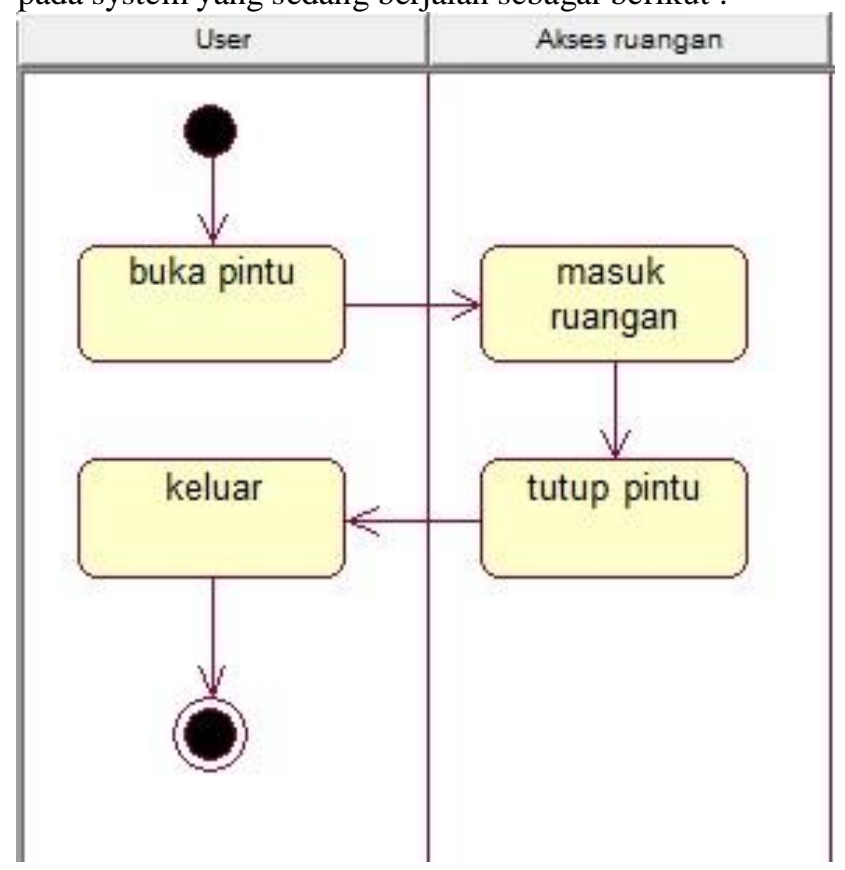

Gambar 1. Activity Diagram analisa sistem berjalan akses ruangan

\section{B. Analisa Kebutuhan}

Analisa Kebutuhan dalam Sistem Keamanan Ruangan dengan Perekaman Visual berbasis Radio Frequency Identification dan Hypertext Processor (PHP) meliputi analisis kebutuhan Sistem, analisis kebutuhan user, analisa kebutuhan admin, analisa kebutuhan proses, analisa kebutuhan output sistem keamanan ruangan, analisa kebutuhan perangkat keras / hardware, dan analisa perangkat lunak / Software.

1) Analisa Kebutuhan User

Kebutuhan yang dibutuhkan oleh user pada Sistem Keamanan Ruangan dengan Perekaman Visual berbasis Radio Frequency Identification dan Hypertext Processor (PHP) ini adalah :

- Sistem Kemanan yang meminimalisir tindakan kejahatan

- Mempunyai data data penggunaan ruangan atau akses keluar masuk ruangan

\section{2) Analisa Kebutuhan Admin}

Kebutuhan yang dibutuhkan oleh admin pada sistem kemanan ruangan ini berbasis web ini meliputi :

- Melakukan proses login terhadap sistem.

- Mengolah data admin. 


\section{3) Analisa Kebutuhan Proses}

Kebutuhan proses adalah kebutuhan pengolahan data dari input data yang diberikan kepada sistem sehingga menghasikan output. Kebutuhan proses tersebut antara lain :

- Proses registrasi user

- Proses Login

- Proses pengelolaan database

\section{4) Analisa Kebutuhan Output Sistem Keamanan Ruangan}

- Terbukanya ruangan

- Informasi mengenai waktu penggunaan user

\section{5) Analisa Kebutuhan Perangkat Keras / Hardware}

Untuk membuat aplikasi Sistem Informasi Geografis berbasis web dibutuhkan perangkat keras komputer agar program aplikasi yang dibuat dapat bekerja dengan baik. Adapun spesifikasi hardware yang diusulkan untuk mengelola sistem informasi geografis ini adalah :

Tabel 1. Spesifikasi Kebutuhan Hardware

\begin{tabular}{|c|l|l|}
\hline No & \multicolumn{1}{|c|}{ Kebutuhan } & \multicolumn{1}{c|}{ Spesifikasi } \\
\hline 1 & PC Server & Intel( $R$ ) coreTM i3 CPU \\
\hline 2 & RFID & Windows \\
\hline 3 & Modul Microcontroller & ATMegal6 \\
\hline 4 & Modul Aktuator & Selenoid, Motor Servo \\
\hline 5 & Modul Sensor & Sensor Laser \\
\hline
\end{tabular}

\section{6) Analisa Perangkat Lunak / Software}

Software yang digunakan untuk mendukung dan merancang pembuatan Sistem Kemanan Ruangan dengn Perekaman Visual berbasis Radio Frequency Identification harus sesuai dengan kebutuhan. Perangkat lunak yang digunakan adalah :

Tabel 2. Spesifikasi Kebutuhan Software

\begin{tabular}{|c|l|l|}
\hline No & \multicolumn{1}{|c|}{ Kebutuhan } & \multicolumn{1}{|c|}{ Spesifikasi } \\
\hline 1 & Sistem Operasi & Microsoft Windows 7 \\
\hline 2 & Pemograman & CVAVR \\
\hline 3 & Visual Basic \\
& Pemograman dan Layar & $\begin{array}{l}2010 \\
\text { XAMPP }\end{array}$ \\
\hline 4 & Data Base & Dreamweaver \\
& Layar Interface Admin & CS \\
\hline 6 & Media Browser & Mozilla Firefox \\
\hline
\end{tabular}

\section{Perancangan Sistem}

Tujuan utama dari perancangan sistem adalah memberikan gambaran perancangan sistem yang akan dibangun dengan mempertimbangkan berbagai faktor-faktor permasalahan dan kebutuhan yang ada pada sistem. Upaya yang dilakukan adalah dengan berusaha mencari kombinasi penggunaan teknologi dan perangkat lunak yang tepat sehingga diperoleh hasil optimal dan mudah diimplementasikan.

Perancangan system kerja merupakan tindak lanjut dari sebuah proyek yang akan dikerjakan dimana dalam perancangan system kerja dapat digambarkan dalam diagram blok sebagai acuan secara keseluruhan system agar mudah dipahami alur dan cara kerja suatu system yg dirancang. Adapun urutan - urutan proses dalam system ini dapat dijabarkan secara umum dalam bentuk diagram blok.

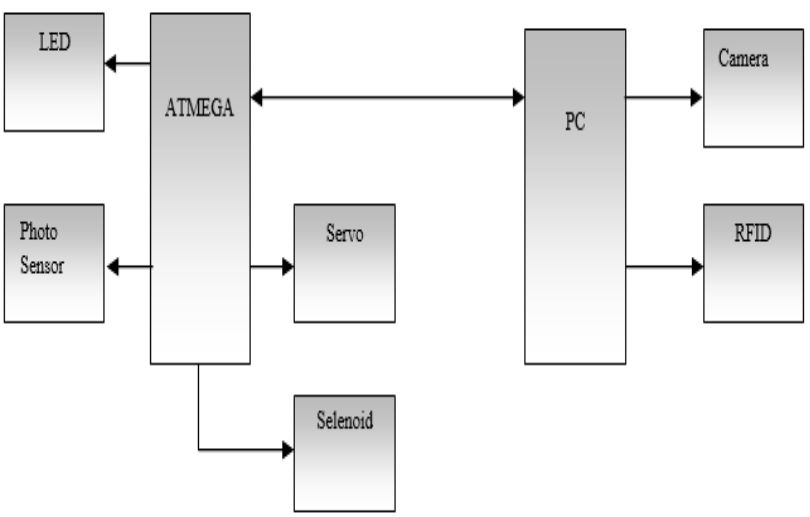

Gambar 2. Diagram Balok Perancangan

\section{1) Perancangan Input Proses Output}

a) Rangkaian Input

- RFID

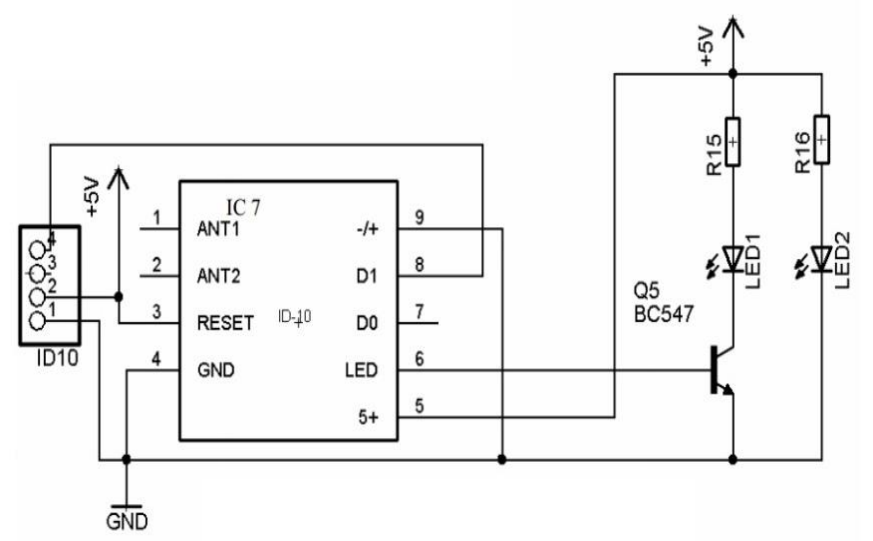

Gambar 3. RFID

- Sensor Laser 


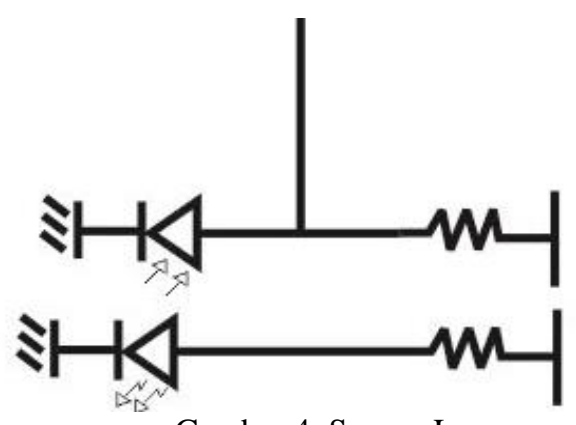

Gambar 4. Sensor Laser

- Sensor Pintu

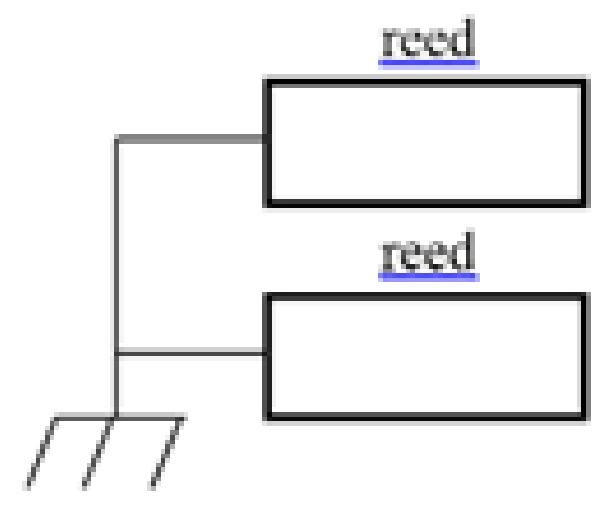

Gambar 5. Rangkaian Sensor Pintu

\section{b) Rangkaian Proses Mikrokontroller}

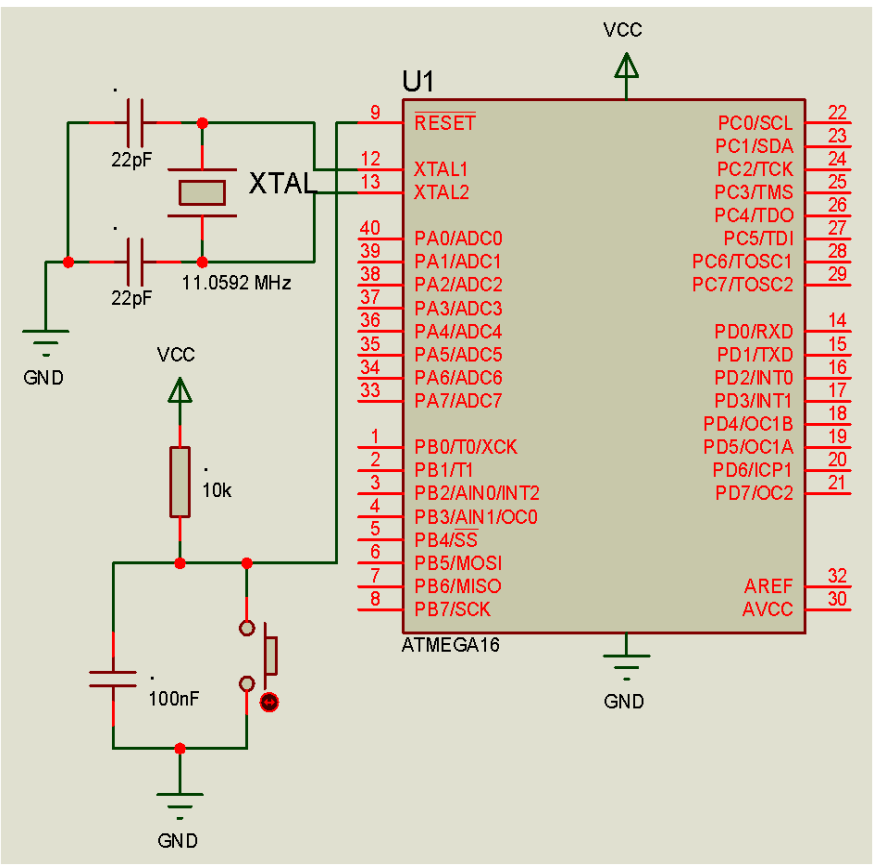

Gambar 6. Rangkaian Proses Mikrokontroller
- Motor Servo

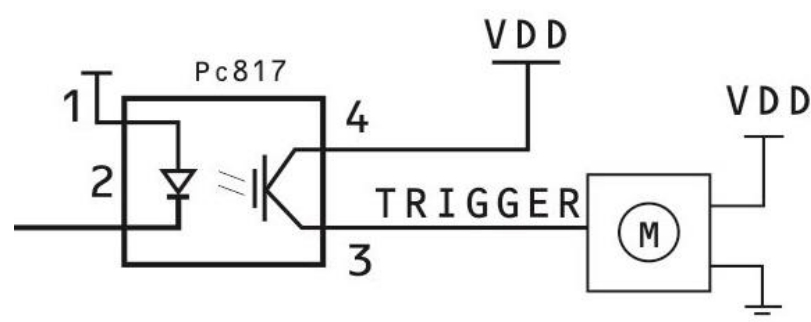

Gambar 7. Rangkaian Motor Servo

- Solenoid

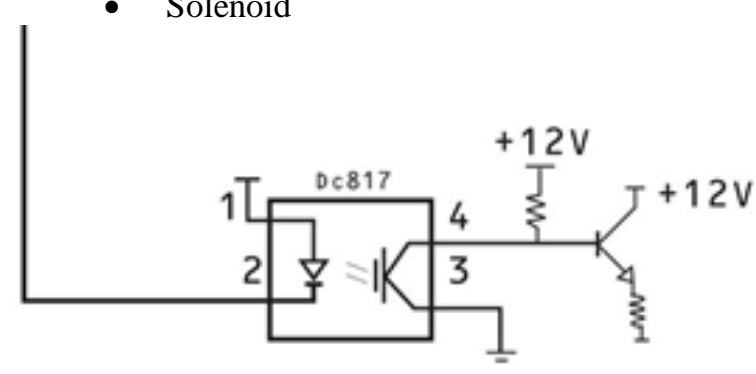

Gambar 8. Rangkaian Solenoid

- Led

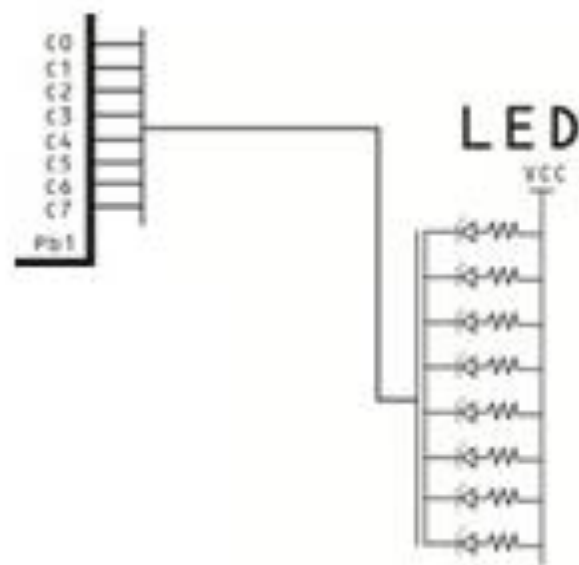

Gambar 9. Rangkaian Lampu LED

2) Perancangan Modul Mikrokontroller ATMEGA 16

Modul ini berfungsi sebagai pengendali utama pada sistem, dimana tugasnya adalah mengolah data dari RFID, mengatur komunikasi ke Modul Aktuator, Modul, LCD, Modul Servo, Modul Selenoid dan Komputer. Modul ini sendiri menggunakan dock speed $11,0592 \mathrm{MHz}$ yang bersumber dari X-TAL dan 2 buah kapasitor berosilasi. Berikut adalah skema Microcontroller ATMega16 :

c) Rangkaian Output 


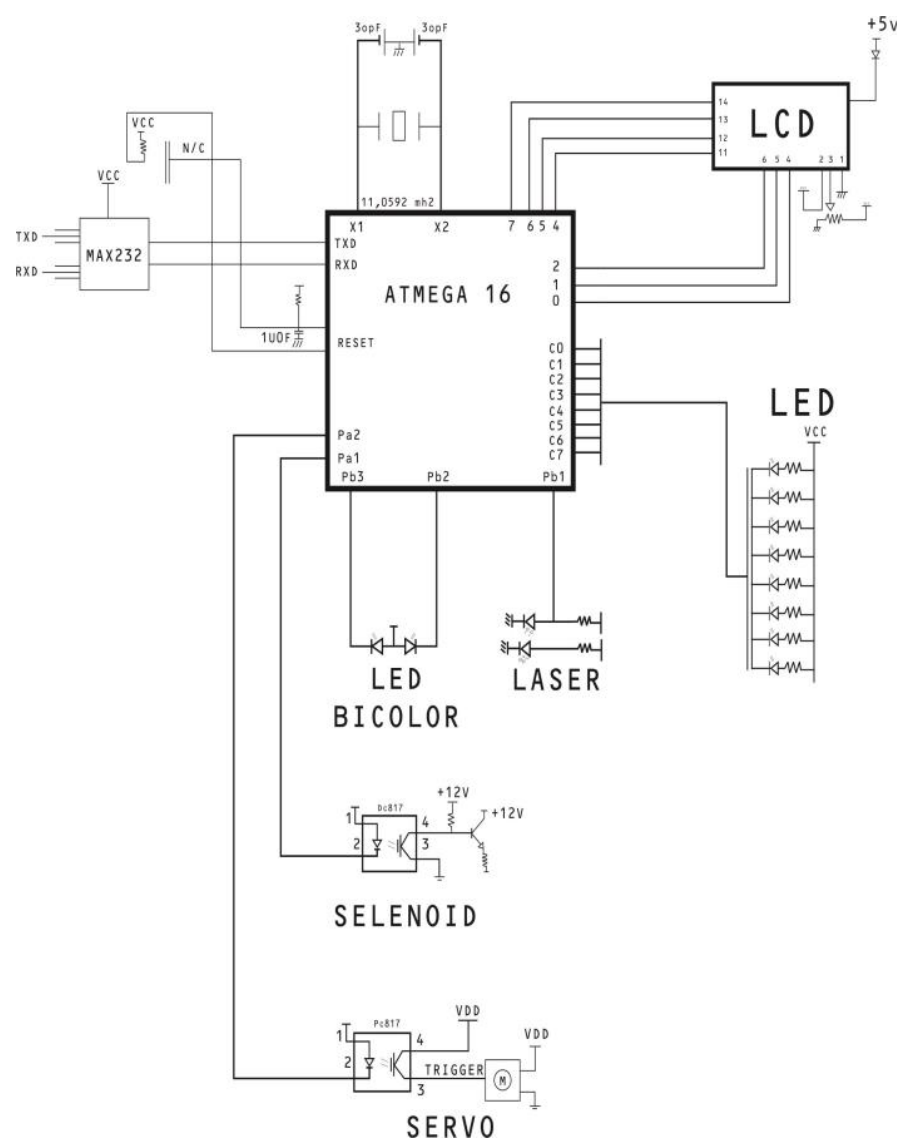

Gambar 10. Rancangan Modul Mikrokontroller ATMEGA 16

\section{3) Perancangan Modul Sensor}

Modul sensor terdiri dari photo diode dan reed switch. Fungsi photo diode untuk mendeteksi apakah seseorang sudah melewati pintu, jika user sudah melewati pintu maka pintu akan menutup otomatis. Reed Switch berfungsi sebagai mendeteksi pergerakan pintu, apakah pintu telah terbuka sempurna, jika pintu sudah menutup dengan sempurna maka akan member sinyal kepada uC.

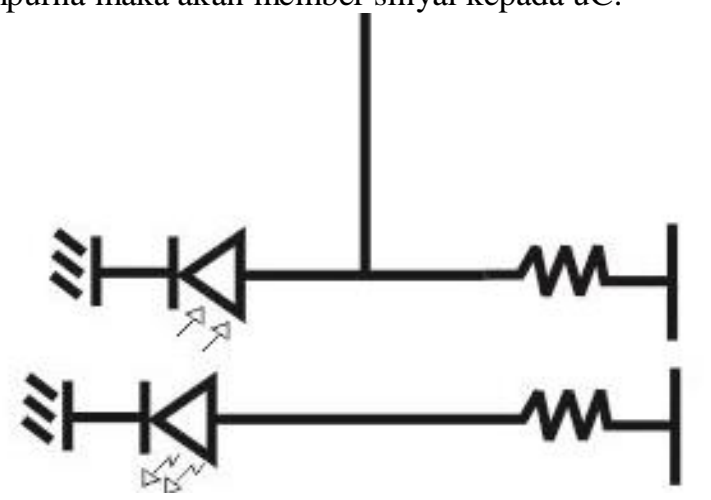

Gambar 11. Skema Modul Sensor

Berikut adalah flowchart modul sensor:

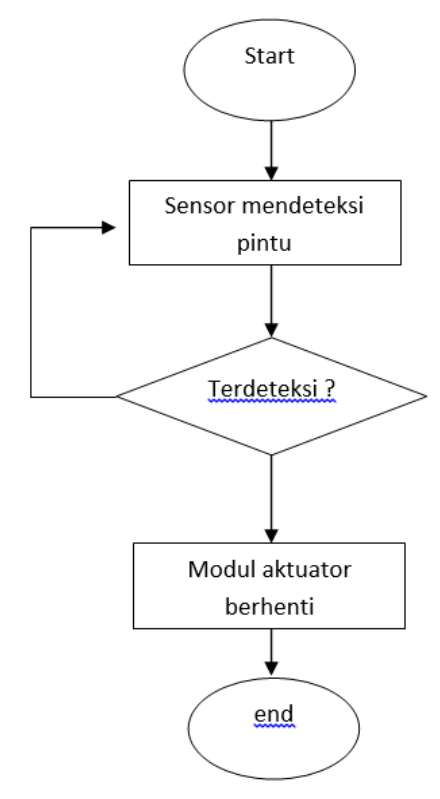

Gambar 12. Flowchart Model Sensor

\section{4) Perancangan Modul Aktuator}

\section{a) Selenoid}

Solenoid berfungsi sebagai penjaga pintu selalu dalam posisi terkuncipabila pintu dalam kondisi tertutup. Cara kerja solenoid ketika diberi arus listrik, kawat yang dibentuk menjadi koil menerima arus. Medan magnet yang dihasilkan menarik besi atau batang baja dengan kuat. Batang yang dihubungkan pada sebuah pegas bergerak ke kumparan dan akan tetap pada posisinya sampai arus dihentikan, kondisi pegas saat ini menjadi tertekan. Ketika arus dimatikan, pegas kembali ke posisi semula dan menarik batang besi atau baja pada posisi awalnya.

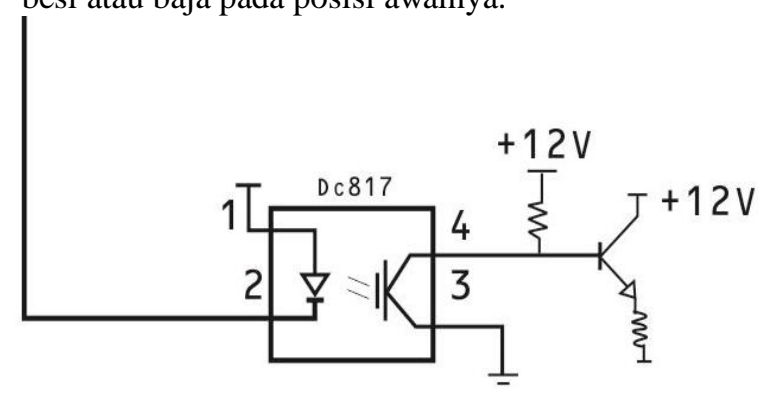

Gambar 13. Skema selenoid

\section{b) Motor Servo}

Motor Servo berfungsi untuk mengerakkan arah pintu. Motor servo dikendalikan dengan memberikan sinyal modulasi lebar pulsa (Pulse Wide Modulation / PWM) melalui kabel kontrol. Lebar pulsa sinyal kontrol yang diberikan akan menentukan posisi sudut putaran dari poros motor servo. Sebagai contoh, lebar pulsa dengan waktu $1,5 \mathrm{~ms}$ (mili detik) akan memutar poros motor servo ke posisi sudut $90^{\circ}$. Bila pulsa lebih 
pendek dari 1,5 ms maka akan berputar ke arah posisi $0^{0}$ atau ke kiri (berlawanan dengan arah jarum jam), sedangkan bila pulsa yang diberikan lebih lama dari 1,5 ms maka poros motor servo akan berputar ke arah posisi $180^{\circ}$ atau ke kanan (searah jarum jam).

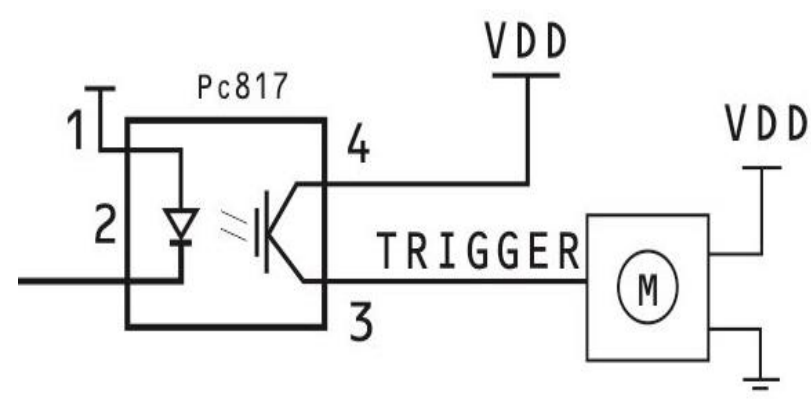

Gambar 14. Skema motor servo

\section{5) Perancangan Modul RFID Reader}

Perancangan modul RFID Reader ini menggunakan Chip RFID tipe ID 10. Led akan menyala ketika ada kartu Tag yang lewat melalui reader. Output dari modul ini merupakan kode ASCII.

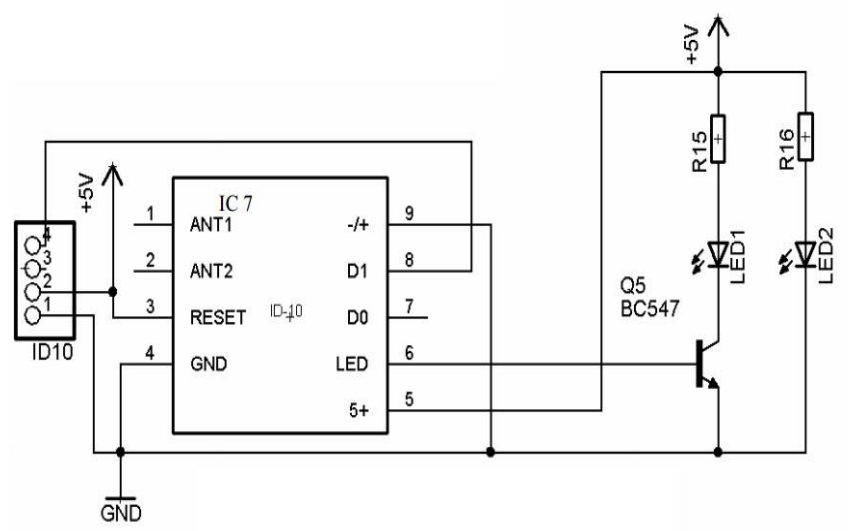

Gambar 15. Skema RFID Reader

\section{IMPLEMENTASI DAN PENGUJIAN}

\section{1) Implementasi}

Implementasi merupakan tahapan pengembangan perencanaan menjadi kode program, dimana pada tahap ini akan menunjukan suatu program dan alat siap dioperasikan. Pada awal bagian akan dijabarkan spesifikasi hardware dan software pada program yang diimplementasikan.

\section{a) Instalasi Perangkat Keras}

- Instalasi Modul Microcontroller

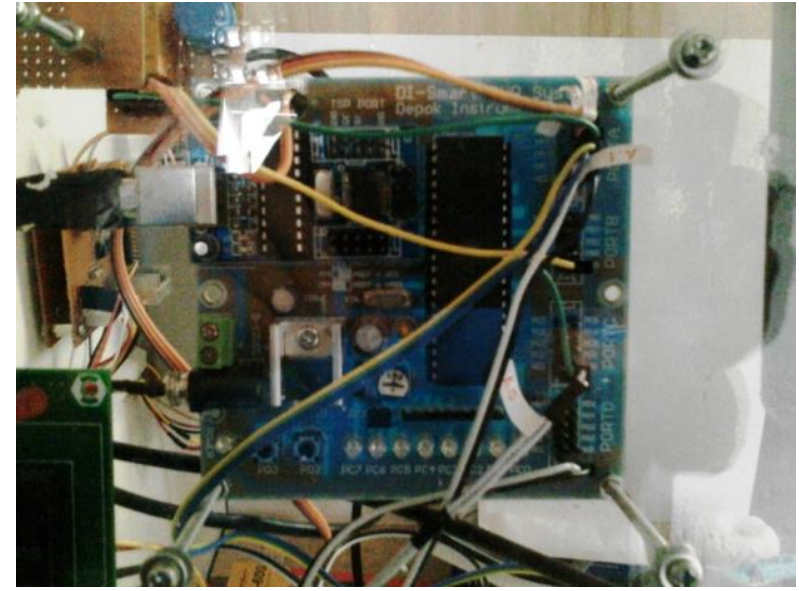

Gambar 16. Instalasi modul microcontroller

- Instalasi Modul Sensor

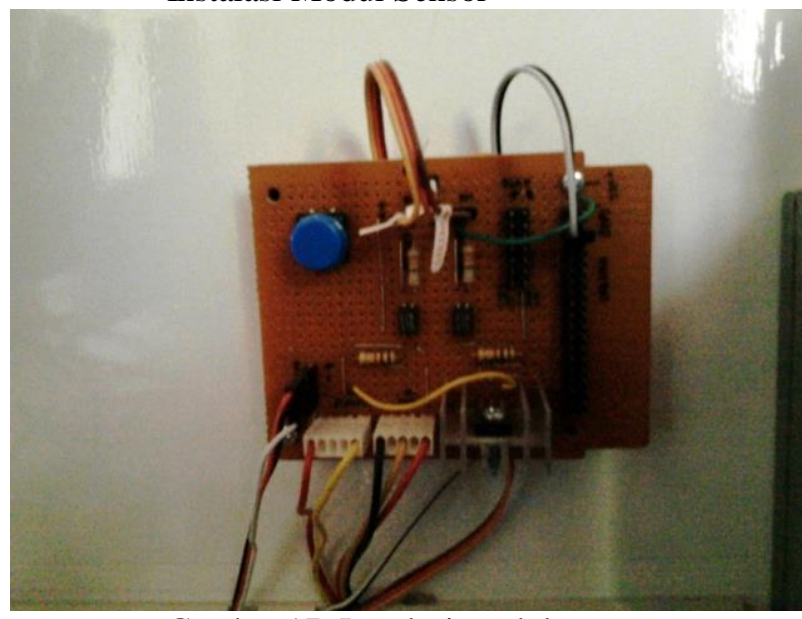

Gambar 17. Instalasi modul sensor

- Instalasi Modul Aktuator

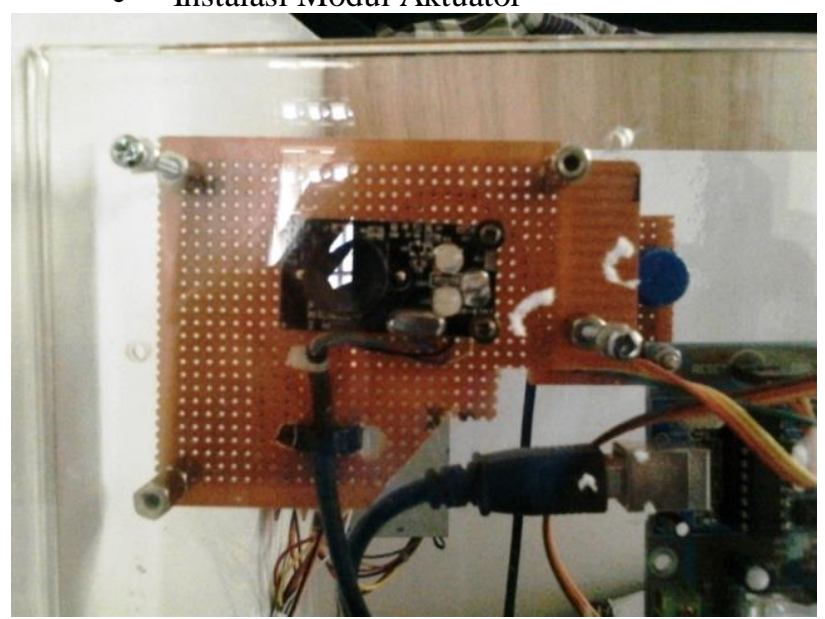

Gambar 18. Instalasi Modul Aktuator

- Instalasi Modul RFID Reader 


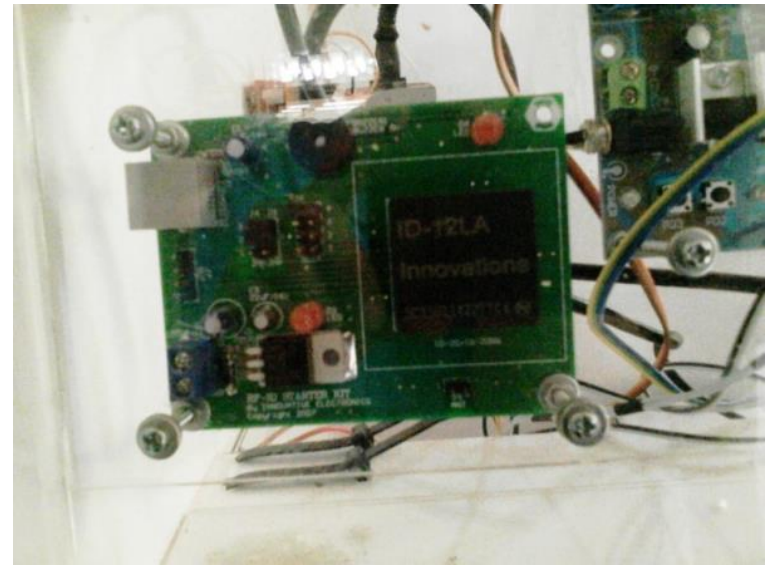

Gambar 19. Instalasi Modul RFID Reader

\section{2) Tampilan Layar}

- Tampilan layar login

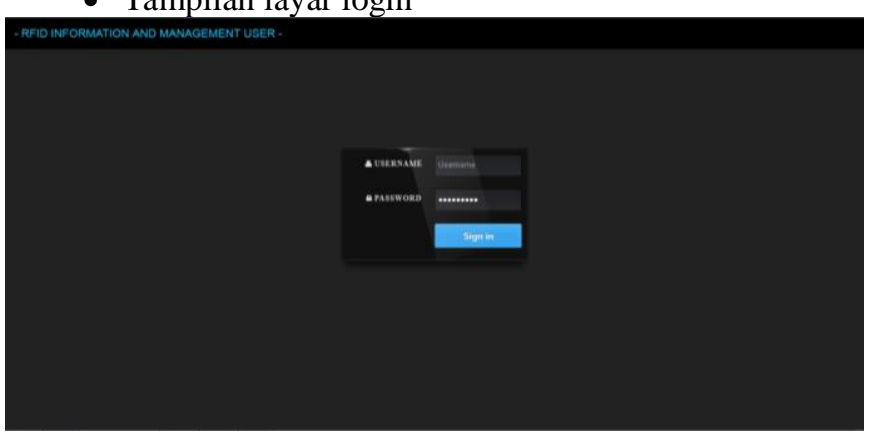

Gambar 20. Tampilan layar login

- Tampilan layar Dashboard Admin

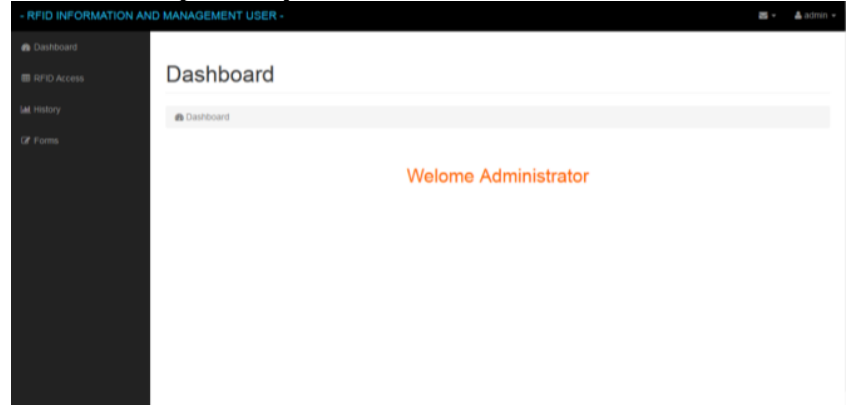

Gambar 21. Tampilan Layar Dashboard Admin

- Tampilan layar RFID Access

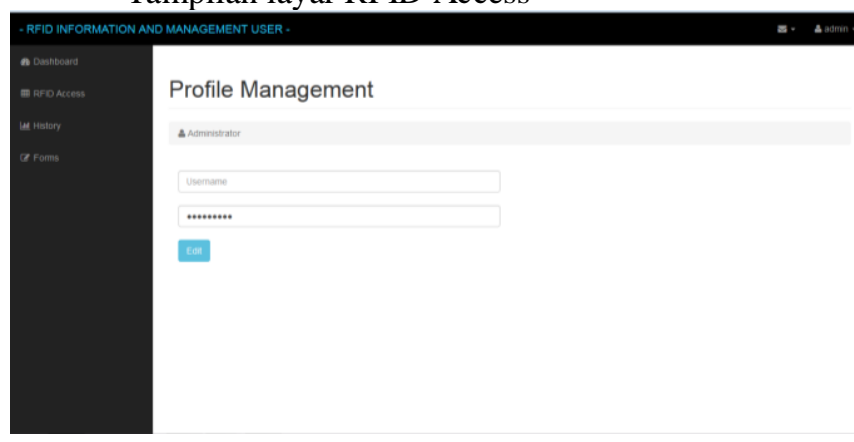

Gambar 22. Tampilan layar RFID Access
- Tampilan Layar History

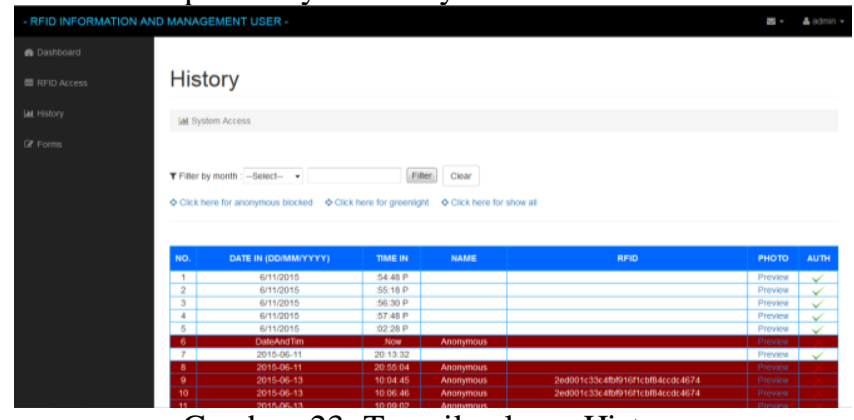

Gambar 23. Tampilan layar History

- Tampilan Layar Form User

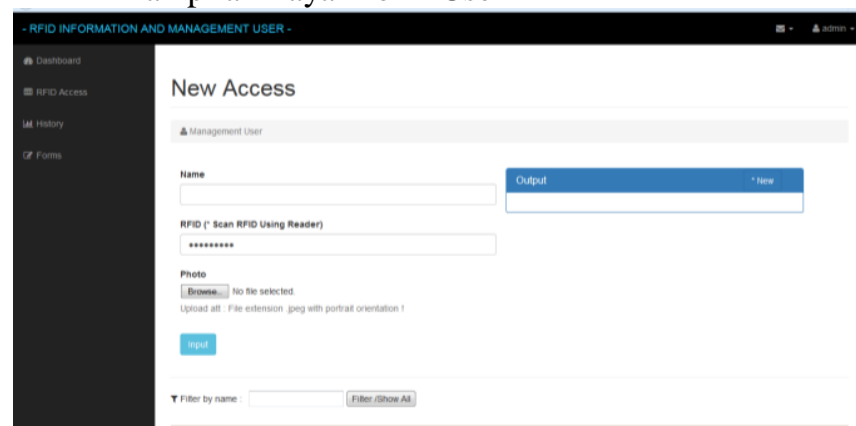

Gambar 24. Tampilan layar Form User

\section{3) Pengujian}

Pengujian sistem dimaksudkan untuk menguji semua elemen-elemen perangkat lunak yang dibuat apakah sudah sesuai dengan yang diharapkan. Berikut antar muka tampilan sistem ini.

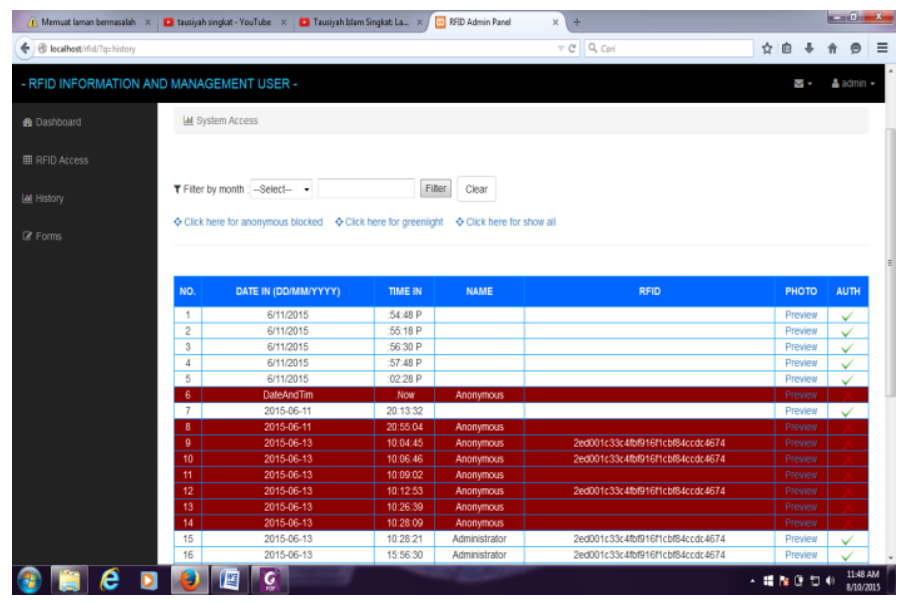

Gambar 25. Tampilan hasil database yang berjalan

Pengujian dilakukan pada sistem menggunakan metode Black Box yang akan memeriksa apakah sistem dapat berjalan dengan benar sesuai dengan yang diharapkan. Adapun teknik ujicoba yang digunakan dalam pengujian black box pada aplikasi ini, yaitu menggunakan teknik sample testing dan behaviour testing. Pengujian ini dilakukan pada proses input data. Pengujian ini melibatkan data real yang didapat secara 
langsung tanpa memperhatikan detail internal dari sistem.

\section{Penutup}

\section{A. Kesimpulan}

Teknologi RFID saat ini dapat diimplementasikan menjadi berbagai aplikasi yang bermanfaat, salah satunya adalah Sistem Keamanan Ruangan ini. Dalam skripsi ini telah dilakukan peracangan dan implementasi Sistem Kemanan Ruangan dengan Perekaman Visual berbasi Radio Frequency Identification (RFID) dan Pre Hypertext Processor (PHP). Berikut adalah beberapa hal yang dapat disimpulkan dari implementasi sistem ini :

- Tag RFID dapat membaca sempurna kode user

- Modul-modul bekerja dengan bagus, baik perangkat lunak ataupun perangkat keras

- Koneksi antara RFID dan Database sudah terhubung dengan baik

- Database bekerja dengan baik, semua user yang masuk terdata oleh

\section{B. Saran}

Sistem ini tidak lepas dari kekurangan dan kelemahan. Oleh karena itu, penulis memberi beberapa saran yang dapat digunakan sebagai acuan dalam penelitian atau pengembangan selanjutnya, yaitu sebagai berikut:

- Agar perangkat ini dapat digunakan dari jarak yang lebih jauh maka diperlukan alat penguat sinyal radio.

- Mengoptimalkan kamera yang digunakan agar hasil tangkapan gambar lebih baik.

- Menambahkan LCD pada sistem agar komunikasi antara user dengan sistem dapat lebih baik.

- Menambahkan PIN agar sistem keamanan lebih

\section{DAFTAR PUSTAKA}

[1] Supandri, Muhammad. 2002 Konsep keamanan pada Radio Frequency Identification. Bandung : ITB

[2] Ranita, Krista Hutabarat. 2002 Perancangan RFID. Pontianak:Universitas Tanjungpura

[3] http://core.ac.uk/download/pdf/12344167.pdf (diakses 6 Juni 2015)

[4] http://eprints.binus.ac.id/2909/1/2008-2-00455SK\%20Abstrak.pdf (diakses 5 Juni 2015) 